\title{
CONHECER A HISTÓRIA E O MODO DE VIDA DOS POVOS INDÍGENAS DE RORAIMA: ETNIAS MACUXI E WAPICHANA
}

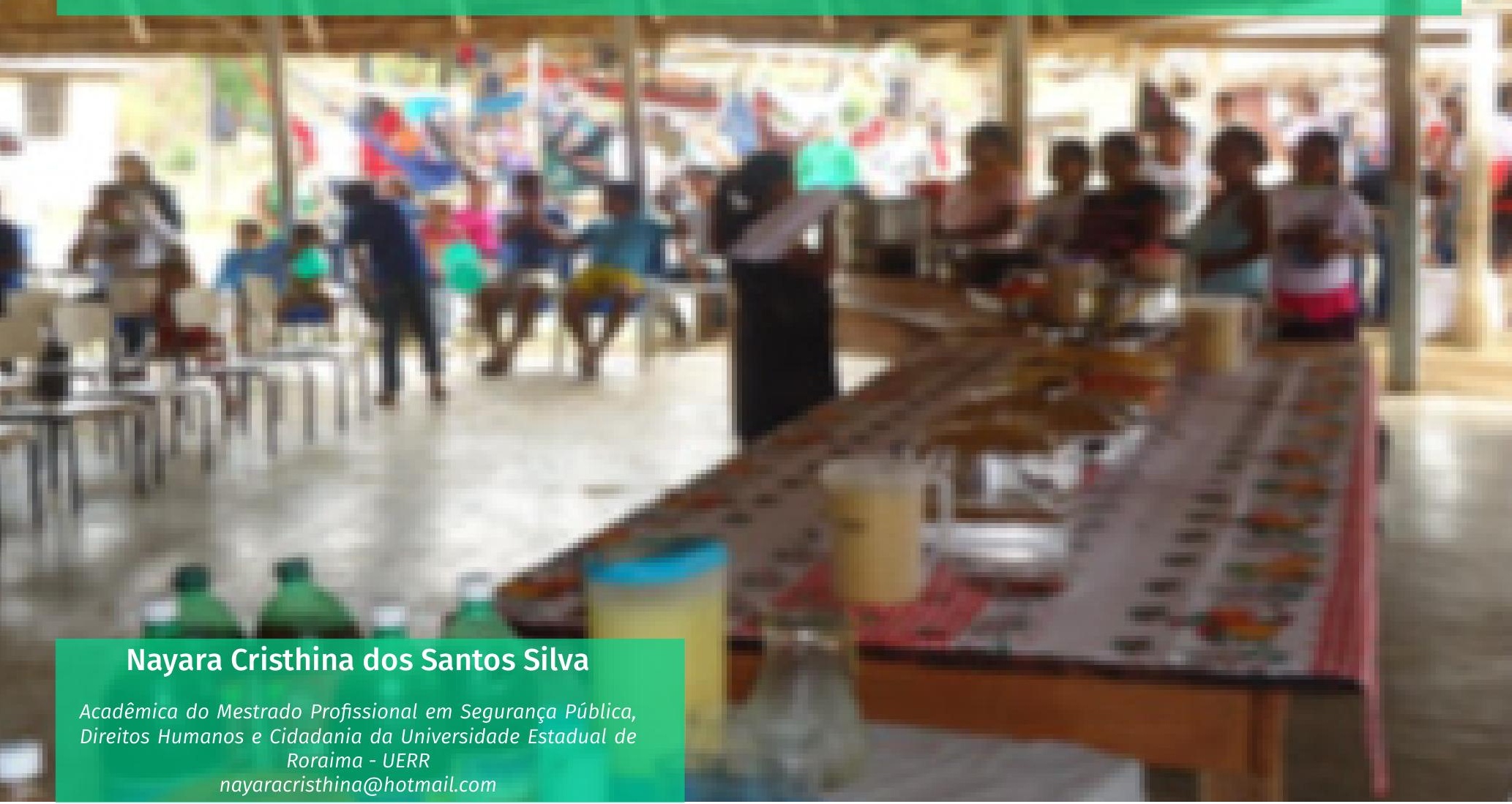

RESUMO

Objetivou-se com esse trabalho reunir relevantes discussões para divulgação e valorização etnocultural dos Macuxi e Wapichana de Roraima para preservação e conservação de suas identidades. A duas etnias possuem a população mais numerosa e representativa entre os povos indígenas encontrados no Estado. Os estudos, as pesquisas e o mais importante a publicação no meio científico das informações sobre a vida dos povos indígenas é de suma importância para o conhecimento da origem e evolução da rica cultura dos povos que vivem nessa terra.

Palavras - chave: Etnocultural, sociodiversidade, valorização.

\section{ABSTRACT}

The objective of this work was to gather discussions for the dissemination and ethnocultural valorization of the Macuxi and Wapichana de Roraima for the preservation and conservation of their identities. The two ethnic groups have the largest and most representative population among the indigenous peoples found in the State. The studies, the researches and the most important the publication in the scientific environment of the information about the life of the indigenous people is of paramount importance for the knowledge of the origin and evolution of the rich culture of the peoples that live in this land.

Keywords: Ethnocultural, sociodiversity, appreciation. 


\section{INTRODUÇÃO}

OBrasiléreconhecidointernacionalmente por sua enorme biodiversidade como também por sua sociodiversidade. Segundo IBGE (2010) os povos contribuem para o incremento da diversidade cultural brasileira com uma população de aproximadamente $817 \mathrm{mil}$ pessoas, 270 etnias e 180 línguas indígena distinta.

Em 2018 a Fundação Nacional do Índio apontou a existência de 11 etnias divididas em 32 terras regularizadas e mais 2 em estudo apresentando as seguintes etnias: Makuxí, Wapixana, Jaricuna, Taulipáng, Ingarikó, Waimiri Atroari, Mawayána, Yanomámi, Wai-Wai, Karafawyana e Katuena (FUNAI, 2018). Santili (2001) afirma que em termo proporcional, o Estado, possui a maior população indígena do Brasil com $46 \%$ da área de terras demarcada como Terra Indígena (ISA, 2011).

Os povos das etnias Macuxi e Wapichana são os mais populosos e os que se destacam marcando presença nas universidades, nas organizações indígenas supraétnicas, como o Conselho Indígena de Roraima-CIR e a Organização dos Professores Indígenas de Roraima-OPIR (LISBOA, 2017). Apresentam origens de grupos linguísticos distintos, no entanto, alguns costumes e culinárias parecidos principalmente por na maioria das aldeias haver o convívio das duas etnias.

Nesse contexto, o estudo sociocultural e ainda de discriminação dos povos em etnias têm como papel dar identidade ao indivíduo ou grupo social de acordo com origem em um ancestral comum, língua, suas tradições, sua mitologia e sua cosmologia próprias. Proporciona também o estudo, a pesquisa e conhecimento de um grupo específico. Com isso, objetivou-se com esse trabalho reunir relevantes discussões para divulgação e valorização etnocultural dos Macuxi e Wapichana de Roraima para preservação e conservação de suas identidades. Como metodologia de pesquisa, foram utilizados documentos científicos, provenientes de base de dados como Scielo, Capes etc., foram reunidos para elaborar uma revisão bibliográfica, mostrando estudos e pesquisas envolvendo o modelo de vida e tradição das etnias supracitadas. Falar sobre os povos Macuxi e Wapichana é muito dificil, pois são poucas referências atuais que destacam a cultura e costumes que caracterizam essas etnias. Ainda, estuda-las separadamente também foi um grande desafio, pois a maioria das aldeias, encontradas no Estado, é composta pela união dessas e até outras etnias.

\section{DISCUSSÃO}

\section{O conceito de etnia e formação da identidade indígena}

A origem da palavra etnia veio do grego, do adjetivo ethnikos, que significa "gentio", que derivou do substantivo ethnos, que significa gente ou nação estrangeira (DEIN, 2006; METEOS, 2007).

O termo etnia passou a ser usado para melhor representar a diversidade cultural. Nesse contexto, Silva e Silva (2006) afirmaram que o termo etnia pode ser amplamente usado para identificação de um grupo humano baseado em laços culturais compartilhados, por possuir característica polivalente, construindo a identidade de um sujeito numa definição determinada pelos critérios de: parentesco, religião, língua, território compartilhado e nacionalidade, além da aparência física.

Munanga (2003) diz que a etnia tem conteúdo social-cultural, histórico, psicológico e conceitua-a como:

[...] um conjunto de indivíduos que, histórica ou mitologicamente, têm um ancestral comum; têm uma língua em comum, uma mesma religião ou cosmovisão; uma 
mesma cultura e moram geograficamente num mesmo território. Algumas etnias constituíram sozinhas nações. Assim o caso de várias sociedades indígenas brasileiras, africanas, asiáticas, australianas, etc. que são ou foram etnias nações (MUNANGA, 2003, p.7).

Para Pujada (1993) a etnia fundamenta-se do acúmulo de heranças e de características peculiares da cultura de um grupo social, o que determina sua existência em um ancestral comum e suas distinções perante outros grupos sociais/étnicos.

No dicionário de sociologia (WILLENS, 1961 apud OLIVEIRA, 2003, p. 134) Emilio Willens define etnia como:

Grupo biológica e culturalmente homogêneo [..]. Os membros de uma etnia possuem traços somáticos em comum, fazendo parte de uma divisão racial mais ampla. Ao mesmo tempo caracterizam- se por uma relativa uniformidade cultural. Há etnias que vieram a constituir nações. Outras vezes, porém, uma nação abrange várias etnias.

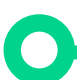

No Brasil, a questão indígena foi marcada por grande luta pela organização e consolidação de direitos e de cidadania e sobrevivência de sua identidade e conservação da sua cultura. No passado o Brasil foi acusado internacionalmente de ter uma política de extermínio de Índios. No ponto de vista colonizadora, adquirir uma identidade "cristã" seria de suma importância para o "índio", pois ser cristão dava ao índio o direito de fazer parte da "civilização". (CARVALHO JÚNIOR, 2005). Ainda, segundo CMI (2003, p. 14):

Até 1988, a política indigenista, de acordo com as Constituições de 1934, 1946, 1967 e 1969, tinha a finalidade de promover a incorporação dos índios à comunhão nacional. Essa orientação estava associada à relativa incapacidade dos índios inscrita no Código Civil. Foi originada na idéia de que os índios, só poderiam se tornar cidadãos plenos, se abandonassem as suas tradições e passassem a se orientar pelos valores da sociedade brasileira.

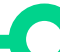

O primeiro órgão criado e estabelecido em 1910 foi o serviço da proteção do índio (SPI) substituído na nomenclatura em 1967 pela Fundação Nacional do Índio (FUNAI) responsável pelos assuntos indígenas. $\mathrm{Na}$ década de 70 aos anos 90 esse órgão tinha como finalidade integrar o índio, pois tinham a imagem de um índio sem cidadania e incapaz (GOMES, 2006). Como pode ser observado na definição de índio pelo artigo 3o do Estatuto do Índio de 1973 que diz: "I - Îndio ou Silvícola É todo indivíduo de origem e ascendência précolombiana que se identifica e é identificado como pertencente a um grupo étnico cujas características culturais o distinguem da sociedade nacional" (Lei № 6.001, De 19 De Dezembro De 1973. TíTULO I Dos Princípios E Definições). Já na Constituição Federal de 1988, é garantida às populações indígenas a cidadania plena, satisfazendo com isto o princípio da igualdade (art. $5^{\circ}$.), quanto reconhece nelas uma diferença identitária, que está expresso no caput do art. 231 " São reconhecidos aos índios sua organização social, costumes, línguas, crenças e tradições, e os direitos originários sobre as terras que tradicionalmente ocupam, competindo à União demarcá-las, proteger e fazer respeitar todos os seus bens."

A identidade é construída através simbologia das características sociais, sendo que, tudo que se mostra diferente, nesse processo, é passível de exclusão pela sociedade. (SILVA, 2009). Nesse contexto, os "índios" passaram a se autodeterminar e agir como tais por ser uma população diferente da europeia a qual lhes denominou "indio", afirmando assim o contraste àqueles com quem foram forçados a conviver (CARVALHO JÚNIOR, 2005).

A mudança nos princípios sociais tem se modificado ao longo dos anos, o que diz respeito ao exercício da cidadania com garantia de direitos e ainda na construção justa e equilibrada das relações sociais, econômicas, culturais e ambientais. Nesse contexto, o indígena tem lutado pela sobrevivência 
e permanência de suas representações simbólicas. Diferentemente do que pregava a política de integração e extinção do índio no passado (GOMES, 2006).

Mas por que esses povos são até hoje denominados indígenas? Segundo dicionários da língua portuguesa, a palavra índio significa nativo, natural de um lugar. No entanto sabemos que essa designação advém de um erro náutico, quando em 1492, na viagem que Colombo empreendeu para as índias e aportou na América, atribuiu aos habitantes desta terra a denominação genérica de índios, conservada até o presente. Porém, cada índio pertence a um povo, identificado por uma denominação própria [...] Cada um dos mais de 230 povos brasileiros gosta de ser reconhecido pelo seu nome próprio, entretanto todos reconhecem a importância de uma denominação que os identifique e os una nas lutas comuns como povos originários do Brasil e da América. (BERGAMACHI, 2008, p. 8-9).

A identidade e a cultura segundo (BORTOLON, 2014) são os elementos que dão legitimidade de um grupo. Por que são definidas pelas características, interesses comuns, sentimentos de pertencer, nacionalidade, padrões comportamentais, preservação da língua e reivindicações sociais, políticas, religiosas e econômicas. No entanto, a pesar da influência do não índio no cotidiano de muitos povos indígenas, questões referentes à preservação e conservação se suas características estão bastante discutidas e valorizadas. Como afirma Baniwa (2006, p. 39):

Os povos indigenas do Brasil vivem atualmente um momento especial de sua história no período pós-colonização. Após 500 anos de massacre, escravidão, dominação e repressão cultural, hoje respiram um ar menos repressivo, o suficiente para que, de norte a sul do país, eles possam reiniciar e retomar seus projetos sociais étnicos e identitários. Culturas e tradições estão sendo resgatadas, revalorizadas e revividas. Terras tradicionais estão sendo reivindicadas, reapropriadas ou reocupadas pelos verdadeiros donos originários. Línguas vêm sendo reaprendidas e praticadas na aldeia, nas escolas e nas cidades. Rituais e cerimônias tradicionais há muito tempo não praticados estão voltando a fazer parte da vida cotidiana dos povos indígenas nas aldeias ou nas grandes cidades brasileiras.

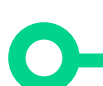

Estudos e pesquisas que buscam documentar e divulgar as práticas, as características e os costumes dos povos indígenas colaboram para a valorização cultural e principalmente no que diz respeito à preservação e conservação de suas identidades. Não para congelar a evolução e ou desenvolvimento dos povos, mas sim para garantir que suas origens e tradições não se percam com a influência de outros povos e principalmente com o surgimento e introdução das inovações tecnológicas nos aldeamentos.

\section{Índios de Roraima}

O Estado de Roraima, segundo Paulo Santili (2001) possui, em termo proporcional, a maior população indígena do Brasil. Atualmente $46 \%$ da área de terras é demarcada como Terra Indígena (ISA, 2011).

O Instituto Brasileiro de Geografia e estatística (IBGE, 2016) estimaram que, a população é formada por 505,665 habitantes sendo desses $95 \mathrm{mil}$ índios, onde $55 \mathrm{mil}$ habitantes das 470 comunidades indígenas e 35 mil índios citadinos (CONSELHO INDÍGENA DE RORAIMA).

Os índios de Roraima dividem-se em várias tribos, discriminadas de acordo com as especificidades de seus costumes, crenças e tradições (FREITAS, 2009). A FUNAI aponta a existência de 11 etnias divididas em 32 terras regularizadas e 2 em estudo. As etnias são as seguintes: Makuxí, Wapixana, Jaricuna, Taulipáng, Ingarikó, Waimiri Atroari, Mawayána, Yanomámi, Wai-Wai, Karafawyana e Katuena. E as terras são: Ananás, Anaro, Aningal, Anta, Araçá, Barata Livramento, Bom Jesus, Boqueirão, Cajueiro, Canauanim, Jabuti, Jacamim, Malacacheta, Mangueira, Mangueira, 
Manoa, Moskow, Muriru, Ouro, Pirititi, Pium, Ponta da Serra, Raimundão, Raposa Serra do Sol, Santa Inez, São Marcos - RR, Serra da Moça, Sucuba, Tabalascada, Trombetas/ Mapuera, Truaru, Waimiri-Atroari, WaiWái, Yanomam (FUNAI, 2018) segundo a figura 1 a seguir:

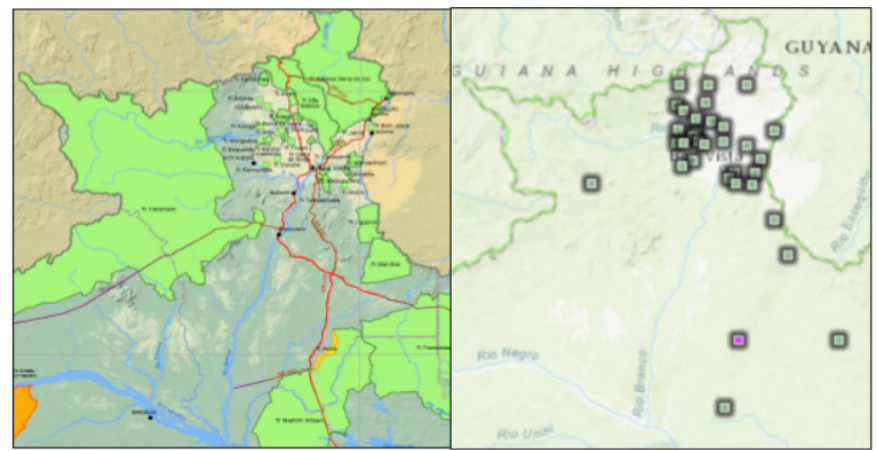

Figura 1: Mapa de Terras Indígenas de Roraima apresentando a distribuição dos territórios indígenas pelo Brasil classificadas segundo situação jurídico-administrativa até 2017.

Fonte: Adaptada do ISA (2018).

A diversidade linguística também pode ser identificada no Estado de Roraima incluído área urbana na capital Boa Vista. Segundo Cunha (2012) são faladas aproximadamente doze línguas indígenas: Macuxi, Wapichana, Yanomami, Wai-Wai, Taurepang, Ingarikó, Yékuana, Patamona, Waimiri-Atroari, Sanuma, Yanomama e Atoraiu.

Destarte, este trabalho abordará sobre os Macuxi e Wapichana por que representam as etnias com maior índice populacional e ainda por suas ações participativas e representativas nas organizações, nas universidades com objetivo de lutar por seus direitos por terra e principalmente à preservação e à conservação de sua cultura.

\section{Conhecendo os Macuxi Wapichana de Roraima}

Os Macuxi são indígenas originários da bacia do Orinoco, que migraram para Roraima devido aos conflitos intertribais e, depois, devido ao contato com europeus (espanhóis, portugueses e ingleses) que adentraram nos territórios indígenas visando escravizar esses povos (AMODIA, PIRA, 1985). São pertencentes ao grupo de família linguística karib, ou caribe, fazem parte do grupo pemón, grupo este que, além desta região brasileira, habita o sul do Estado Bolívar (Venezuela) e parte da Guiana (BURGARDT, 2015).

Segundo Paulo Santilli (2001), tem como habitat a área chamada Circum-Roraima, que compreende as vertentes meridionais do Monte Roraima, as savanas e campos, indo até a cabeceira dos rios Branco e Rupununi, na Guiana Inglesa. Aimberé (2009) classificouos em: Macuxi do lavrado (Romoko) e Macuxi das serras (Vi'rikó).

A grafia das palavras Makuxi e Karib segundo Rodrigues (1986) segue a convenção promovida pela Associação Brasileira de Antropologia 1953.

Os Macuxi são a etnia mais populosa, com aproximadamente 30 mil pessoas no Estado de Roraima, distribuídos em 22 terras indígenas (LISBOA, 2017). Em destaque na figura 2:

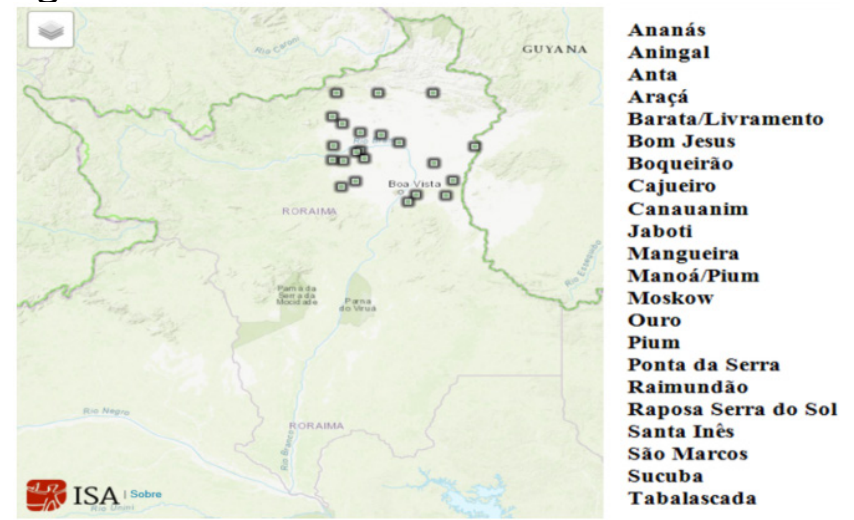

Figura 02. Mapa de distribuição da etnia Macuxi. Fonte: Adaptada do ISA (2018).

Dessas a mais populosa é a TI Raposa Serra do Sol, na porção central e mais extensa de seu território, que compreende uma extensão territorial de 1.7 milhões de hectares, comportando aproximadamente 21 mil pessoas (DISEI-LESTE, 2015 apud FERNANDES, 2015), divididas entre 201 aldeias ou "comunidades". 
A distribuição espacial da população Macuxi faz-se em várias aldeias e pequenas habitações isoladas, formadas por parentelas interligadas por casamentos. No entanto, observa-se o casamento entre indivíduos de aldeia diferentes. (PIB, 2018).

$\mathrm{Na}$ organização político-social temse como líder o tuxaua e seu vice. Além de existirem categoria subordinadas que são os capatazes, (auxiliares que cuidam dos setores rurais da maloca), e os vaqueiros, (que lidam diretamente com o gado), todos escolhidos pela comunidade. O tuxaua é a representatividade máxima na comunidade e tem a função de administrá-la político, social e economicamente (FREITAS, 2003). As decisões e debates importantes são realizados em reuniões junto à comunidade no malocão ou nas escolas (LISBOA, 2017). Como afirma Mongiano (2011):

[...] O poder do tuxaua nunca é um poder de comando. o chefe é a pessoa mais sábia. A decisão final é tomada pelo chefe, mas de maneira coletiva: a comunidade tem sua solução para os problemas. O chefe não pode ter poder absoluto, mas tem que realizar aquilo que a comunidade quer. o poder é compartilhado; o chefe ouve a comunidade que pode decidir, também, substituí-lo, se não satisfeito (MONGIANO, 2011, p. 91).

Buscando a não dizimação do seu povo, devido aos grandes conflitos entre os "indios" e "brancos", consequência da invasão das terras, os Macuxis e outras etnias principalmente os Wapichana, também buscaram se organizar para reivindicares o direito a sobrevivência sendo assim apoiaram em ONG's e nas igrejas católicas e principalmente surgiram com suas lutas o Núcleo de Educação Indígena - NEl; Conselho Indígena de Roraima - CIR; a Comissão dos Professores Indígenas do Amazonas, Roraima e Acre - COPIAR e da Coordenação das Organizações Indígenas da Amazônia Brasileira - COIAB e Organização dos Professores Indígenas de Roraima- OPIR (FREITAS, 2003). O indígena luta no mundo moderno pela preservação e conservação de sua língua, cultura, costumes entre outros e ainda o direito à terra de onde foram obrigados a saírem. Essas instituições têm representação nacional e regional e as etnias Macuxi e Wapichana são predominantes.

Segundo Freitas (2003) os Macuxi não são plenos caçadores por tradição. No passado pescavam e coletavam frutos silvestres. Com a diminuição do território e até devido às características ambientais e devido ao abandono das práticas tradicionais de aquisição de alimentos passaram a criar animais de pequeno porte, como galinhas e porcos, ou o cultivo de milho, feijão, batata, arroz, mandioca e frutas, como banana, laranja, melancia, abacaxi e manga, e ainda o consumo de produtos industrializados (FOTOGRAFIA 1d). Os rebanhos de gado coletivos, pequenos, são obtidos através de projetos iniciados pela Diocese de Roraima, pela FUNAl e pelo governo do Estado de Roraima. Ação teve origem na década de 70 com o projeto "vaca para o índio" da igreja católica como apoio aos índios de Roraima na estratégia de resistência (FREITAS, 2003; PIB, 2018).

Avisão e relação do Macuxi com a natureza partem de uma origem cosmológica onde 0 universo se divide em três planos. O plano superior, denominado Kapragon, é habitado por diversos tipos de seres (corpos celestes e animais alados). o plano intermediário se caracteriza como sendo a superficie terrestre vivem o homem e os animais, além dos os Omá:kon, seres que habitam as serras e as matas e os Makoi, habitam o meio aquático. No plano subterrâneo, são os Wanabaricon, seres semelhantes aos humanos, porém de pequena estatura, que plantam roças, caçam, pescam e constroem aldeias (SANTILI, 2002; CASTRO, 2007; PIB, 2018). Partindo desse a visão que segundo (CASTRO, 2007) que se explica o misticismo e a ação dos xamãs para a cura dos índios quando os seres subterrâneos 
os capturam as almas, ainda sobre a origem do monte Roraima, de outras etnias e até do cultivo de espécies vegetais.

Para Silva (2001) os povos indígenas compartilham mitos e crenças. Explica ainda, que "o intercâmbio entre povos era explicitado ao longo do calendário indígena de eventos tradicionais, as grandes festas 'rituais do parixara (folha de inajá), do tucui (beija-flor) e do arerúi (ou Aleluia, de influência externa anglicana) - com as quais promoviam um notável intercâmbio entre grupos locais" (SILVA, 2001).

$\mathrm{Na}$ festa paiwari e nos rituais religiosos (nos rituais xamânicos e nos rituais Aleluia) via-se a execução das danças e os cantos. As danças parixara e o tukui eram um sinal de boas-vindas a visitantes (Figura 3a) (Schomburgk, 1845).

A festa do paiwari, denominada dessa forma em referência a principal bebida consumida com exclusividade pelos índios durante as festas, produzida à base da raiz da mandioca "brava" (Manihot esculenta), cujo preparo e teor alcoólico se distingue do caxiri, consumido no cotidiano (FERNANDES, 2015). O autor ainda classificou por gêneros ou variantes musicais segundo seus repertórios antigas festas de paiwari, serenkanto, cantos xamânicos, piai, de cantos e danças do Aleluia, musicais de forró, repertórios de parixara e tukui, repertórios de forró politicamente engajados, cantos de trabalho, kesékeyelemú; canções de ninar, cantos de vaqueiros; e cantigas jocosas.

Nesse contexto, de mudança global e influência dos brancos na cultura e em busca da sobrevivência Cavalcante (2010, p.77), faz uma observação que as antigas festas de paiwari se "modificaram para continuar existindo [...]: a carne de caça foi substituída pela de gado (Figura 3c), as danças tradicionais, tukui e parixara, deram lugar ao forró" (Figura 3b).

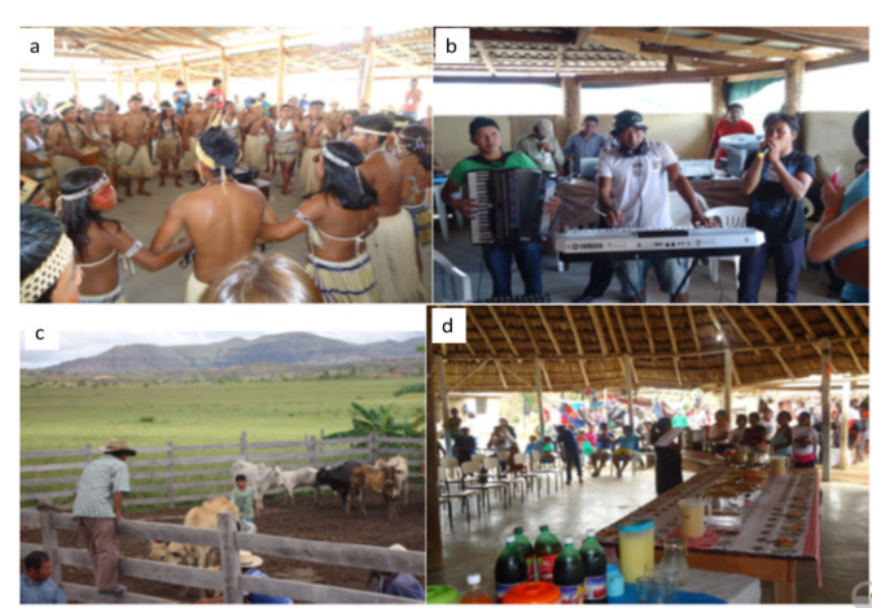

Figura 03: Apresentação parixara, forró na comunidade, criação de gado e banquete em cerimônia Macuxi.

Fonte: Adaptada de Fernandes (2015).

O povo da etnia wapixana ou Wapichana é origináriodo tronco linguístico Arwak, e constituem a maior população, afiliada geneticamente à famíla lingüística Arawak. ou Aruak também sendo conhecido como Maipure (ISA, 2010; IBGE, 2010). Segundo Rodrigues (1986, p.65) “Aruák ou Arawák é o nome de uma língua falada na costa guianesa da América do Sul, na Venezuela, na Guiana, no Suriname e na Guiana Francesa".

O Centro de Informação da Diocese de Roraima (1989) citado por Lima (2013) afirma que ao grupo Wapichana foi formado a partir da junção de, pelo menos, quatro grupos distintos pertencentes ao mesmo tronco linguístico, são eles os Vapidiana verdadeiro, Atoraiu, Amaripá e Maopityan. Hoje em dia só restariam duas dessas subdivisões, os Vapidianas verdadeiros e os Atoraiu.

Essa etnia ocupa território tanto do Brasil como da República Cooperativa da Guiana. Sua área de habitação tradicional é o interflúvio dos rios Branco e Rupununi, na fronteira entre - Brasil e a Guiana. Segundo Braga e Silva (2011) em território brasileiro ocupam além de áreas do vale do rio Uraricoera, e nas regiões do Surumu e Amajari, onde as aldeias são em sua maioria mistas Wapichana e Macuxi ou Wapichana e Taurepang, ocupam também a porção nordeste de Roraima, onde as aldeias 
Wapichana localizam-se predominantemente na região conhecida por Serra da Lua, entre o rio Branco e o rio Tacutu. Santo A (2010, p. 91/92) explica a origem a dinâmica dessa ocupação:

Até o ano de 1905, os índios Macuxi e os Jaicuna dominavam a região dos altos da Serra de Pacaraima (Pacaraima), enquanto os Wapixana dominavam as fraldas da mesma serra Nessa época [....]. Sua ocupação foi, aos poucos, se tornando muito extensa. Do Leste da Serra de Pacaraima (Pacaraima), desceram para as terras altas das cabeciras do Maú, de onde avançaram para regiões do rio Tacutu, Serra do Cuano-Cuano, rio Majari (Amajari) e Oeste da ilha de Maracá.

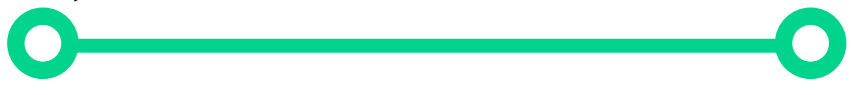

Ainda, o $\operatorname{CIDR}$ (1989, p. 82) mostra que a formação do aldeamento misto surgiu posterior a grandes batalhas para domínio de território:

[...] a guerra que mais durou e que foi, sem dúvida, decisiva para o futuro do Território, os Macuxi travaram com os wapixana. Provenientes do Norte, os Macuxi lutaram com os wapixana para a conquista da região localizada ao norte do Rio Branco. Foram anos de hostilidades, através dos quais estes dois povos tiveram possibilidades de se conhecerem e, uma vez acabadas as guerras, de conviverem pacificamente até hoje.

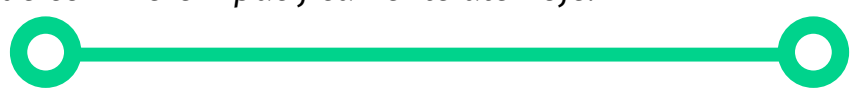

Essa etnia apresenta o segundo maior índice populacional indígena do Estado de Roraima contabilizando aproximadamente 11 à 13 mil indivíduos (ISA, 2010; IBGE, 2010). Ocupando 24 terras indígenas como aldeamentos localizados predominantemente na região conhecida por Serra da Lua (Figura 4) (PIB, 2018):

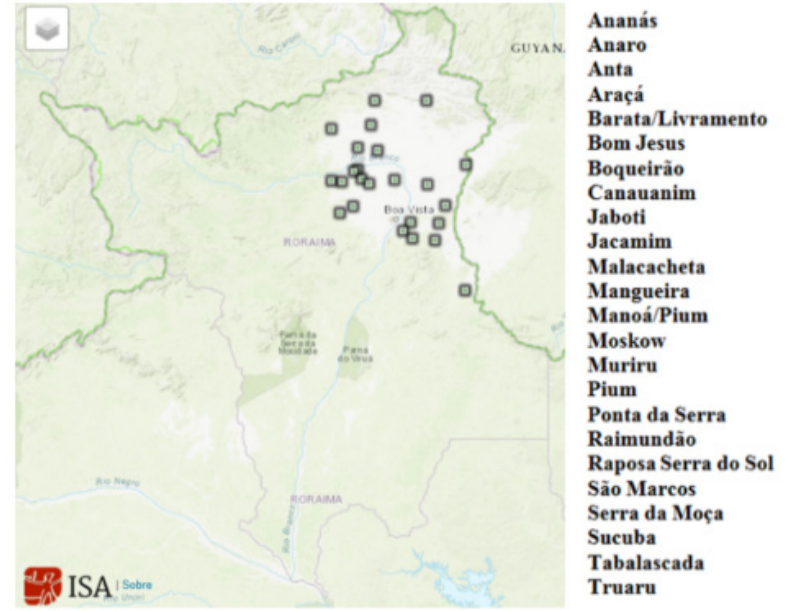

Figura 04: Mapa de distribuição da etnia Wapichana. Fonte: Adaptada do ISA (2018).

Assim como o povo Macuxi, os Wapichana também possuem narrativas que explicam a significância das paisagens ecológicas, o surgimento da diversidade genética vegetal e a constituição dos povos indígenas da região.

O Macuxi narra sobre o mito do Makunaima enquanto os Wapichanas narra como o criador de todas as coisas Tuminikery (Deus) e os dois irmãos Duid e Mauaré, eram ajudantes Tuminikery na criação do mundo, e ainda temos a grande árvore conhecida como Tamoromu de onde se obtinha todos os alimentos. Duid o irmão mais novo foi responsável pela derrubada da grande árvore (WIRTH, 1950 citado por SOUSA, 2013). Na narrativa da queda da árvore, segundo Santos (2006 citado por LIMA, 2013) Duid é criador de uma paisagem particular, um conjunto de distintas formas que enuncia as heranças que representam as sucessivas relações entre 0 homem e seu ambiente.

Outros mitos que podem ser encontrados como, por exemplo, é o Kanaimî entidades malignas que agiam por intermédio de um feiticeiro ou até por tribos rivais. Segundo (CIRINO, 2008, 124) Tuminikery ensinou seu povo a evitar perigos, doenças e maus espíritos, pois poderiam causa a morte. Dentre as entidades, o Kanaimî era mais perigoso por que podia causar males físicos e a morte. Ele pode atuar, além de formas humanas, 
em outras formas como onça, cobra e outros animais.

O xamã é denominado marinao ou marinau, que na atualidade são como o rezador, o benzedeiro. Este incorpora entidade dos antepassados e através dos cantos denominados Marinaokanu podem curar almas doentes. O que não possui esse dom de canto é considerado xamã do mal (CARNEIRO, 2007; PIB, 2018). Como descreve Farage (1997) citado por Silva (2013, p.62):

[...] o ritual xamânico inicia com os cantos do marynaukanu que são acompanhados pelo ritmo de um molho de folha de ingá de cacho ou de pau tipiti para subir, ou seja, para deixar o corpo e permitir que outras entidades, em especial, o espirito de um marynau já morto se manifeste por meio do seu corpo, enquanto sua alma Uduronaa visita os habitantes invisiveis das serras $e$ outros locais. O princípio vital do marynau permanece ligado ao seu corpo por meio deste canto corrente e, por esse motivo, em guerras xamânicas, um marynau tentará cortar a corrente de seu adversário.

0

Assim como a etnia Macuxi, os Wapichana possuem a organização social onde o tuxaua é a maior autoridade eleita de uma comunidade indígena seguidos de participação de outros para assessora-lo como o "capataz" e os grupos de lideranças, os professores, agente de saúde, catequistas, vaqueiros, conselheiros etc. todos escolhido em reuniões comunitárias no malocão ou escolas não diferindo das outras etnias.

O que se pode destacar dentro da política social dessa etnia é a participação da comunidade na agricultura onde se destaca a ajuri (um sistema que consisti na ajuda mutua entre famílias quando se pretende abrir uma roça). A família convida os membros "mais chegados" da comunidade para ajudarem nos trabalhos mais pesados. A ajuri abrange os trabalhos iniciais, como a derruba (retirada das árvores de maior porte), broca (retirada de cipós e árvores secundárias) e a coivara (queima do material vegetal) (LIMA, 2013).
No cultivo, a mandioca e macaxeira são as principais espécies, e sempre com maior produção, pois elas são a matéria prima para o preparo de uma variedade de alimentos tradicionais como as bebidas o parikari, o caxiri, a farinha d] água e seca, pajuaru, carimã, mingau, pé de moleque ou bolo, goma, beiju, a tapioca etc. Além do cultivo de bananas, arroz, milho, cana, feijão, jerimum, abóbora, cará, melancia (LIMA, 2013; SILVA, 2013).

Segundo Farage (1997, p. 72) classificação botânica dos Wapixana compreende três grandes categorias:

karam'makao, as plantas da mata, selvagens; wapao'ribao, as plantas domesticadas, cultivadas na roça; e por fim, categoria singular, os wapananinao - cuja tradução, de simplicidade apenas aparente, seria "as nossas plantas" (wa, pronome possessivo, 1a pessoa do plural; pananu, panakaru, planta; nao, pl.). o critério do cultivo diferencia tais grandes categorias, critério que, se de fácil apreensão no contraste entre as plantas da mata e aquelas da roça, complica-se um tanto mais quando nos voltamos à categoria wapananinao, especialmente porque, como espero demonstrar, os wapananinao escapam à esfera do cultivo.

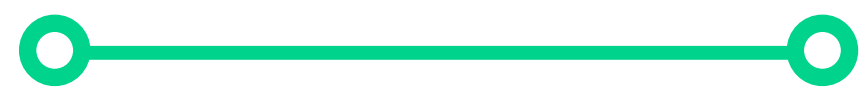

Em pesquisas realizadas por Silva (2013) ele fala que categoria wapananinao é plantada buscando a proteção das casas e roça para ter uma boa colheita (engordando a macaxeira ou mandioca). Ou ainda, usada em vários rituais através de oração "puri" e banhos. Como por exemplo, na caça onde os filhos dos caçadores são banhados, com infusões dessas plantas, que eram de acordo com o animal que seria caçado, isso para proteção dos filhos pequenos para não adoeceram. Também para realização de festas etc.

A pesca e caça são bastante utilizadas e são tarefas realizadas pelo homem e em coletividade. Na pesca usam anzóis em espinhel ou em camorim, a técnica de mascareta, tem-se também o uso de tarafas, malhadore e o timbó, o último, considerado veneno de pesca advindo de plantas. Ainda 
tem a criação dos pesqueiros, um local escolhido onde se coloca alimentos para atrair os peixes por um determinado tempo. Já na caça s duas técnicas mais usada varrida e o moitá (SILVA, 2013).

O mesmo autor diz que há outros rituais que são ainda mantidos por esse povo como, por exemplo, na agricultura o plantio da "mãe da roça", como também a observação das fases da lua para cultivar e colher. Essa última usada também para determinar o tempo certo e respeitando a natureza para tirar madeira e palha, pra caçar e pescar. Além disso, Barreto (2006) mostra que a confecção de alguns objetos é também efetuada através de rituais por isso são considerados sagrados.

As festas os eventos sempre são carregados de atividades que resgatam os valorizam a culturais do povo. São realizadas apresentações da dança tradicionais como parichara. Competição entre participantes da aldeia e com outras aldeias (comunidade) nas habilidades de fiar algodão, trançar darruana, ralar mandioca, tomar pajuaru, comer damurida, flechadas em alvos, corridas pedestres, corrida com tora, subir na bacabeira, queda de corpo entre outras.

A corrida de pedestre está como valor histórico. Pois ela ocorre com o participante carregando a mulher. Silva (2013, p. 120) como diz que:

A brincadeira relata que antigamente um jovem para casar-se com uma jovem tinha que demonstrar aos seus pais ou ao seu povo força e habilidades em dificeis atividades; os que não conseguiam acabavam fugindo com a mulher carregando-a em seu ombro por longa distância, para que, ao ser procurado, o rastejador encontrasse apenas as pegadas de uma pessoa e assim desistia.

A figura (5) a seguir mostra a como é realizada a coivara na preparação da roça (5a), mulheres deitando o beiju na preparação do parikari (5b), a coagem do caxiri (5c), o
Moquém de carne de caça ( $5 d)$, confecção da darruana e a corrida carregando a mulher (5e; f respectivamente).

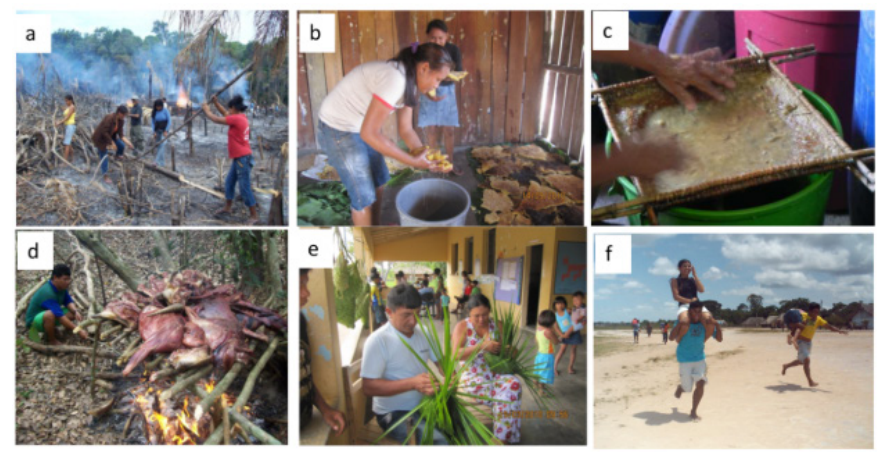

Figura 05: Atividades cultural do povo Wapichana. Fonte: Adaptada de Silva (2012).

\section{CONSIDERAÇÕES FINAIS}

Roraima possui uma rica diversidade cultural com 11 etnias de povos nativos, além de diversos povos que deixaram suas regiões e até seus países e fizeram do Estado sua terra.

O Estado de Roraima não possui uma característica cultural de origem própria. Isso por que essa formação cultural partiu da colonização de uma diversidade de povos. Esses trouxeram consigo suas tradições culturais e com isso contribuíram ainda mais para essa riqueza.

A colonização por holandeses, ingleses e portugueses, e ainda por ser um Estado que faz fronteiras com outros países, a cultura indigena sofreu e vem sofrendo grande influência dessas outas culturas. Principalmente, no passado, no que se referiu o processo de catequização realizado pelos padres no período de colonização do Estado, com o objetivo de tornar o índio um cidadão. E ainda hoje, a religião tem grande poder na vida dos índios.

Nos dias atuais essa característica que define o povo indígena de Roraima, além de ter sofrido influência no passado, também está sofrendo grandes interferências negativas e tem como resultado a perda de muitos costumes, mitos, rituais, músicas, danças, 
língua etc. que somam para a riqueza de sua cultura. Um dos fatores que estão contribuindo para essa perda cultural é a desvalorização da cultura, ou seja, a falta de documentação, pesquisa científica e divulgação, assim como a ausência da valorização interna, na comunidade, com ensinamento dos costumes para os mais jovens. Tudo isso, não para o confinamento de seu povo ou mais para que sua história pare no tempo, mais sim para que seus valores e costumes não se percam com a aquisição de novos conhecimentos.

Falar sobre os povos Macuxi e Wapichana é muito dificil, pois são poucas referências atuais que destacam a cultura e costumes que caracterizam essas etnias. Ainda, estuda-las separadamente também é um grande desafio, pois a maioria das aldeias, encontradas no Estado, é composta pela união dessas e até outras etnias.

Destarte, discriminar através de estudos, de pesquisas e o mais importante da divulgação do campo complexo de informações que envolvem as etnias indígenas de Roraima torna-se importante para a valorização, à preservação e ainda para o conhecimento da origem, evolução e formação identitária da rica cultura e dos povos que vivem nessa terra.

\section{REFERÊNCIAS}

AMODIO, E.; PIRA, V. História dos povos indígenas de Roraima: Makuxi - Ingaricó Taurepaang e Wapixana. Coordenação Loretta Emiri. Boa Vista: Boletim n. 1 - Arquivo Indigenista da Diocese de Roraima, 1985.

BANIWA, G. S. L. 0 índio brasileiro: o que você precisa saber sobre os povos indígenas no Brasil de hoje. Brasília: Ministério da Educação, Secretaria de Educação Continuada, Alfabetização e Diversidade; LACED/Museu Nacional, 2006.

BARRETO, P. D. O. L. A fibra de tucum como alternativa econômica dos povos indígenas do Alto Rio Negro. Manaus: UFAM, 2006.

BERGAMASCHI, M. A. Povos indígenas: conhecer para respeitar. In: BERGAMASCHI, Maria Aparecida (Org.) Povos indígenas e educação. Porto Alegre: Mediação, 2008. 160 p.

BORTOLON, D. M. O. TERRA INDÍGENA ARAÇÁ/RORAIMA: CONTINUIDADES E TRANSFORMAÇÕES ENVOLVENDO COLETIVIDADES MACUXI. 2014. 170 p. Dissertação (Mestrado em ambiente e desenvolvimento) Centro Universitário- UNIVATES. Lajeado-RS. 2014.

BURGARDT, V. H. V. Raposa Serra do Sol: Atas que contam histórias (1977-1998). In: XXVIII Simpósio Nacional de História, 39, 2015, Florianópolis. Lugares dos Historiadores Velhos e Novos Desafios. Anais... Florianópolis-SC, 2015.

CARNEIRO, J. P. J. A. A Morada dos Wapichana: Atlas Topominíco da Região Indígena da Serra da Lua-RR. 2007. 189 p. Dissertaçã (Mestrado em linguística). Faculdade de Filosofia, Letras e Ciências Humanas/ Universidade de São Paulo-USP. São Paulo, 2007.

CARVALHO JÚNIOR, A. D. Índios Cristãos: a conversão dos gentios na Amazônia Portuguesa (1653-1769). Campinas, 2005. Tese (Doutorado) Instituto de Filosofia e Ciências Humanas, Universidade Estadual de Campinas, SP, 2005.

CASTRO, E. V. Sobre outras práticas de conhecimento A natureza em pessoa: In: Encontro "Visões do Rio Babel. Conversas sobre o futuro da bacia do Rio Negro". Instituto Socioambiental e a Fundação Vitória Amazônica, Manaus. 22 a 25 de maio de 2007.

CAVALCANTE, O. C. A politica da memoria Sapara. 2010. 219 p. Tese (Doutorado) - Universidade Estadual de Campinas, Instituto de 
Filosofia e Ciências Humanas, Campinas-SP, 2010.

CIMI-Conselho Indigenista Missionário. Revista Mensageiro, 2003.

CIRD-DIOCESE DE RORAIMA. Índios de Roraima: Macuxi, Taurepang, Ingarikó, Wapixana. Boa Vista, RR, CIRD, Coleção Histórico- antropológica, v. 1, 1989, $106 \mathrm{p}$.

CIRINO, C. A. M. A "Boa Nova" na língua indígena: Contorno da evangelização dos Wapischana no século XX. Boa Vista: UFRR, 2008.

CUNHA, P. Bilinguismo: Discursos de professores em área de fronteira, Bonfim-RR. Boa Vista, 2012. 117 p. Dissertação de Mestrado - Programa de Pós-graduação em Letras da UFRR, Boa Vista-RR, 2012.

DEIN, S. R. culture and ethnicity in minority research: a critical discussion. J Cult Divers. 2006 Summer;13(2):68-75.

FARAGE, N. As flores da fala: práticas retóricas entre os Wapishana. São Paulo, 1997.

FERNANDES, F. M. M. Do parixara ao forró, do forró ao "parixara": uma trajetória musical. 2015. 168 p. Dissertação (Mestrado) -Universidade Federal de São Carlos- UFSCar, 2015.

FREITAS, A. Geografia e História de Roraima. 7. ed. rev. e ampl. Boa Vista, RR: IAF, 2009.

FREITAS, D. B. A. P. Escola Makuxi: identidade em construção. 2003. 234 p. Tese (Doutorado em Linguística Aplicada)-Instituto de Estudos da Linguagem (IEL)/Unicamp. Campinas-SP, 2003.

FUNAI. Disponível em <http://www.funai.gov. br/index.php/indios-no-brasil/terras-indigenas> Acessado em maio de 2018.
FUNAI. O BRASIL INDIGENA. 2010. Disponível em <http://www.funai.gov.br/arquivos/conteudo/ascom/2013/img/12-Dez/pdf-brasil-ind. pdf $>$ Acessado em 05 de maio de 2018.

GOMES, M. C. OUTROS OLHARES SOBRE A QUESTÃO INDÍGENA NA AMAZÔNIA: Cultura e identidade na realidade dos índios na cidade. Em Debate 03. Rev. do Depto. de Serviço Social PUC-Rio. 2006. Disponivel em <https://www.maxwell.vrac.puc-rio.br/9320/9320. PDF>Acessado em 05 de maio de 2018.

IBGE. Atlas Digital do Brasil (2016). Disponível em <http://www.ibge.gov..br/apps/atlas_nacional/>acessado em maio de 2018.

IBGE. População Indígena do Estado de Roraima (Censo demográfico 2010). Disponível em: <http://www.ibge.gov.br/Estadosat/temas. php?sigla=rr\&tema=censodemog2010_indig_ univer> Acesso em maio de 2018.

ISA- TERRAS INDÍGENAS NO BRASIL. Disponível em < https://terrasindigenas.org.br/pt-br/> Acessado 01 de Maio de 2018.

ISA-INSTITUTO SOCIOAMBIENTAL. O caso da demarcação da Raposa-Serra do Sol. On-line, 22/08/2010.

ISA. Diversidade socioambiental de Roraima: subsídios para debater o futuro sustentável da região / [organização Ciro Campos].

-- São Paulo: Instituto Socioambiental, 2011.

LIMA, L. P. N. S. "ILHADOS" Estratégias e feições territoriais Wapichana na Terra Indígena Manoá-Pium. 2013. 155 p. Dissertação (Mestrado em Ciências Sociais, especialista em estudos comparados sobre as Américas) Universidade de Brasília - UnB. Brasília, 2013.

LISBOA, J. F. CADÊMICOS INDÍGENAS EM RORAIMA E A CONSTRUÇÃO DA INTERCULTURALIDADE INDÍGENA NA UNIVERSIDADE: entre a formação e a transformação. 
2017. 316 p. Doutorado em Antropologia social (Pós - Graduação em Antropologia Social) Universidade de Brasília (DAN/UnB. Brasília, 2017.

METEOS, P. A. Review of name-based ethnicity classification methods and their potential in population studies. Popul Space Place. 2007;13:243-63.

MONGIANO, A. Roraima entre profecia e martírio: Testemunho de uma igreja entre índio nas lembranças de Dom Aldo Mongiano, missionário da consolata: Bispo de Roraima desde 1975 até 1996. Tradução de padre Bruno Schizzerotto. Boa Vista, RR: Diocese de Roraima, 2011.

MUNANGA, K. Uma abordagem conceitual das noções de raça, racismo, identidade e etnia. Palestra proferida no $3^{\circ}$ Seminário Nacional Relações Raciais e Educação-PENESB-RJ, em 5 nov. 2003.

OLIVEIRA, R. C. Reconsiderando etnia. Sociedade e Cultura, V. 6, n. 2, jul./dez. 2003, P. 133-147.

PIB/ISA. Povos indígenas do Brasil (PIB). Disponível em<https://pib.socioambiental.org/ pt/Povo:Wapichana\#L.C3.ADngua>Acessado em maio de 2018.

PUJADAS, J. J. Etnicidad: identidad cultural de los pueblos. Madrid: Eudema, 1993.

Revista de Antropologia, vol. 3, $n^{\circ} 1$. Florianópolis, novembro de 2001.

RODRIGUES, A. D. Línguas brasileiras para o conhecimento das línguas indígenas. São Paulo: Loyola, 1986.

SANTILLI, P. J. B. Pemongon Patá: território Macuxi, rotas de conflito. São Paulo: Editora UNESP, 2001.

SANTILLI, P. Trabalho escravo e brancos cani- bais. Uma narrativa histórica Macuxi. In:. ALBERT, B. e RAMOS, A. (organizadores). Pacificando o branco: cosmologias do contato no norte amazônico. São Paulo: UNESP, 2002.

SANTOS, A. J. Roraima: História Geral. Boa Vista: UFRR, 2010.

SCHOMBURGK, R. H. "Journal of an Expedition from Pirara to the Upper Corentyne." The Journal of the Royal Geographical Society of London, v. 15: p. 1-104. 1845.

SILVA, C. J.; BRAGA, Y. C. Terra Indígena Raposa Serra do Sol as Estratégias Das ONGs Indígenas no Setentrião Brasileiro - Revista de Administração de Roraima - RARR, Ed 1, V.1, p 121-144, $2^{\circ}$ Sem - Boa Vista/RR, 2011.

SILVA, G. S. Agroatividade Wapixana na comunidade indígena Canaunim: avanços e ajustes em contato com outras culturas (1960-2010). 2013. 144 p. Dissertação (Mestrado em Sociedade e Cultura na Amazônia) Universidade Federal do Amazonas. Manaus, 2013.

SILVA, O. S. Os Wapixána: uma situação de contato interétnico. In Ilha: SILVA, T. T; (Org.) HALL, S; WOODWAR, K. Identidade e diferença: a perspectiva dos estudos culturais. Petrópolis, RJ: Vozes, 2009. 133p.

SILVA, V. K.; SILVA, H. M. Dicionário de Conceitos Históricos. São Paulo: Contexto, 2006.

TEMPESTA, G. A. A produção continuada dos corpos. Práticas de resguardo entre os Wapichana e os Macuxi em Roraima. 2004. 146 f. Dissertação (Mestrado) - Curso de Antropologia, Departamento de Antropologia do Instituto de Filosofia e Ciências Humanas, Universidade Estadual de Campinas. Campinas, 2004. 